\title{
Bio-co-precipitation of Heavy Metals with Calcium Carbonate in Aqueous Solutions
}

\author{
YUMI KIM AND YUL ROH*
}

Department of Geological and Environmental Sciences, Chonnam National University, Gwangju 61186, Korea

(*correspondence: rohy@jnu.ac.kr)

Microbially induced calcium carbonate precipitation (MICP) is a bio-geochemical precess involving precipitation of calcium carbonate and possiblity of co-precipitation of heavy metals [1]. The objectives of this study were to investigate the extent that a urease-positive bacterium, Sporosarcina pasteurii, can tolerate a range of heavy metals (cadmium, copper, and zinc), and to examine the bio-coprecipitation with calcium carbonate to remove these metallic toxicants from aqueous solutions.

The experiments, using the Sporosarcina pasteurii, were performed aerobically in growth media including urea and 30 $\mathrm{mM} \mathrm{CaCl}$. Each heavy metal such as cadmium, copper, and zinc was injected into the media at a concentration of 0.01 $\mathrm{mM}$ to $1 \mathrm{mM}$, respectivley. To investigate the effect of the heavy metals on microbial growth, sampling was carried out at $1,3,7$, and 14 days after the experimental set-up, and then $\mathrm{pH}, \mathrm{OD}_{600}$, and concentration of metal/Ca were measured by $\mathrm{pH}$ meter, UV-vis, and ICP-OES, respectively. XRD and SEM-EDS were used for mineralogical characterization of the precipitated calcium carbonates.

Microbial growth and urea degradation led to an increase in $\mathrm{pH}$ and $\mathrm{OD}_{600}$, creating an environment favorable for the precipitation of calcium carbonate. Among the metal ions, the microorganisms showed the most sensitive response to $\mathrm{Cd}$ concentration, and microbial growth and calcium carbonate precipitation only occurred when the $\mathrm{Cd}$ concentrations were below $0.5 \mathrm{mM}$. The type and concentration of metal ions contributed to the mineralogy of precipitated calcium carbonate. In the Cd-containing medium, only calcite was formed by the microorganism, while in the $\mathrm{Cu}$-containing medium, both calcite and aragonite were formed. In addition, the microorganisms in Zn-containing media induced precipitation of various calcium carbonates such as calcite, aragonite, vaterite, and monohydrocalcite. Metal ions showed high removal rate with precipitation of calcium carbonate when included in the medium at low concentration ranges from 0.01 to $0.05 \mathrm{mM}$. The removal rates were up to $100 \%$ for $\mathrm{Cd}$ and $\mathrm{Cu}$, and up to $50 \%$ for $\mathrm{Zn}$, respectively. These results indicated that bioprecipitation could be used to remove heavy metals via co-precipitation of heavy metals with calcium carbonate formation from aqueous solutions.

[1] Fujita et al. (2000) Geomicrobiology Journal 17(4), 305-318. 